\title{
Conservation Agriculture as an Alternative for Soil Erosion Control and Crop Production in Steep-slopes Regions Cultivated by Small-scale Farmers in Motozintla, Mexico
}

\author{
R. ROMERO-PEREZGROVAS ${ }^{1,2, *}$, S. CHEESMAN ${ }^{1,3}$ \\ ${ }^{1}$ International Maize and Wheat Improvement Center (CIMMYT), Apdo. Postal 6-641, 06600 Mexico, D.F., Mexico \\ ${ }^{2}$ Katholieke Universiteit Leuven, Department of Earth and Environmental Sciences, Celestijnenlaan 200 E, 3001 Leuven, Belgium \\ ${ }^{3}$ ETHZurich, Institute of Agricultural Sciences, Eschikon 33, 8315 Lindau (ZH), Switzerland \\ *Corresponding author: rromeropg@gmail.com
}

Received October 11, 2014; Revised November 12, 2014; Accepted December 28, 2014

\begin{abstract}
Agricultural activities in steep-slope regions of the world have been increasing in recent years. When annual crops are produced in these regions, high soil erosion rates become a constant threat. An extended body of literature proposes reforestation or plantations with perennial crops as potential solutions. However, such approaches fail to meet the needs of the small-scale farmers who rely on annual crops to produce the lion's share of their food. Another commonly used measure to tackle erosion is the construction of physical barriers - a solution that demands substantial investment, for both implementation and maintenance. Analternative solution is conservation agriculture (CA), which is a cropping system based on three principles: 1) minimal soil disturbance; 2) crop rotations and/or intercropping, and 3) permanent soil cover through crop residue management. Using longitudinal statistical analysis this research - based on survey data (154 observations) collected in 1994 and 2008 within two ejidos of Motozintla in the state of Chiapas, Mexico - found that under CA, maize (Zea mays) and bean (Phaseolus vulgaris) yields remained at minimum consistent, and in some cases increased over time. Maize yields reached 3.3 ton ha ${ }^{-1}$, whilst bean reached $262 \mathrm{~kg} \mathrm{ha}^{-1}$. Maize yields were also consistently higher than the long-term state's average (1987-2012) of 2.3 ton ha ${ }^{-1}$. Moreover, $90 \%$ of the farmers perceived that CA improved soil fertility and 99\% observed that CA effectively controlled erosion. The traditional system in these two ejidos presented a number of enabling characteristics for facilitating CA implementation: no mechanisation was being utilized, intercropping was already a common practice, and the main competitor for crop residue use (ruminants) could eventually be substituted for other livestock such as pigs. This research provides evidence to demonstrate that long-term adoption of CA in a steepslope region can help to control soil erosion whilst allowing farmers to produce their staple crops.
\end{abstract}

Keywords: chiapas, farmer perception, survey data, longitudinal statistical analysis, maize, beans, yield, adoption enabling characteristics

Cite This Article: R. ROMERo-Perezgrovas, and S. CHEesman, “Conservation Agriculture as an Alternative for Soil Erosion Control and Crop Production in Steep-slopes Regions Cultivated by Small-scale Farmers in Motozintla, Mexico.” World Journal of Agricultural Research, vol. 2, no. 6A (2014): 18-24. doi: 10.12691/wjar-2-6A-4.

\section{Introduction}

Soil erosion in steep-slope regions is a constant problem for sustainability when the natural cover has been removed and agriculture based on annual crops is implemented (Tuahn et al. 2014). Researchers have argued that reforestation or plantations with perennial crops offer solutions for soil erosion in steep slopes regions (Lal and Stewart 2013). However, these approaches do not take into account the fact that most of the food being produced by the small-scale farmers normally exploiting such marginal and low-yielding areas comes from annual crops (Altieri 2002). Another approach for soil conservation that includes annual crop production is the building of physical barriers and the creation of terraces (Amsalu and de Graaff 2007): in principle, this approach solves both problems by allowing farmers to produce annual crops and by achieving soil conservation through soil recapture. However, the investments necessitated by these physical modifications of hills and slopes often renders them inaccessible to such small-scale farmers, and transfers of external resources via governments, non-governmental organisations or other outside investments are often needed (Lutz et al. 1994). Another problem evoked by the physical barriers and engineering approach is that such infrastructure requires maintenance and thus additional financial support from other actors and/or sectors in order 
to be preserved and to maintain optimal functionality. Resource constrained governments are normally not willing to implement and maintain in the long term large scale barriers or terraces projects. Of further concern for soil scientists is that since adding barriers and terraces recaptures soil losses, thus alleviating the symptoms of land degradation, soil erosion is not tackledat its source (Lal 1990). Under these circumstances the main question is how to stop soil erosion and allow small-scale farmers to produce the annual crops that account for most of their food intake.

Even conservation agriculture (CA) 'heretics' (Giller et al. 2009) acknowledge the capacity of this technology for soil erosion control, there has been an accumulation of scientific evidence that cropping systems based on 1) minimal soil disturbance, 2) crop rotations and/or intercropping and 3) Permanent soil cover through residue management have a big effect on soil erosion control (Lal and Stewart 2013). CA could be a solution to the dilemma the steep slopes regions faces i.e. how to produce annual crops without eroding the soil. Furthermore, CA does not necessarily needs heavy investments or incentives for its implementation, and can help small-scale farmers to stabilize their yields through time (Erenstein 2003).
This paper gives evidence that long-term adoption of CA is possible in a steep-slopes region cultivated by small-scale farmers.However, this case is rather an exception, and it's important to understand why in this case successful adoption happened whereas in many other regions around the globe with similar characteristics farmers have abandoned CA after the incentives for implementation stopped (Stevenson et al. 2014). We argue that the main drivers of this long-term adoption have been the stability of yields and a big institutional change that pushed farmer towards CA (the use of fire as a pre-sowing activity became illegal in 1985).

\section{Research Area and Data Collection}

\subsection{Description of Motozintla}

The Motozintla region is localized between the $15^{\circ} 03^{\prime}$ $15^{\circ} 38^{\prime}$ of north latitude and $92^{\circ} 02^{\prime}$ - 92 ${ }^{\circ} 40^{\prime}$ west longitude within the south-eastern state of Chiapas in Mexico. The total surface of the region is 2,126. $\mathrm{Km}^{2}$ and it encompasses eight municipalities: 1) Amatenango de la Frontera, 2) Bejucal de Ocampo, 3) Bellavista, 4) El Porvenir, 5) La Grandeza, 6) Mazapa de Madero, 7) Motozintla and 8) Siltepec (Figure 1).

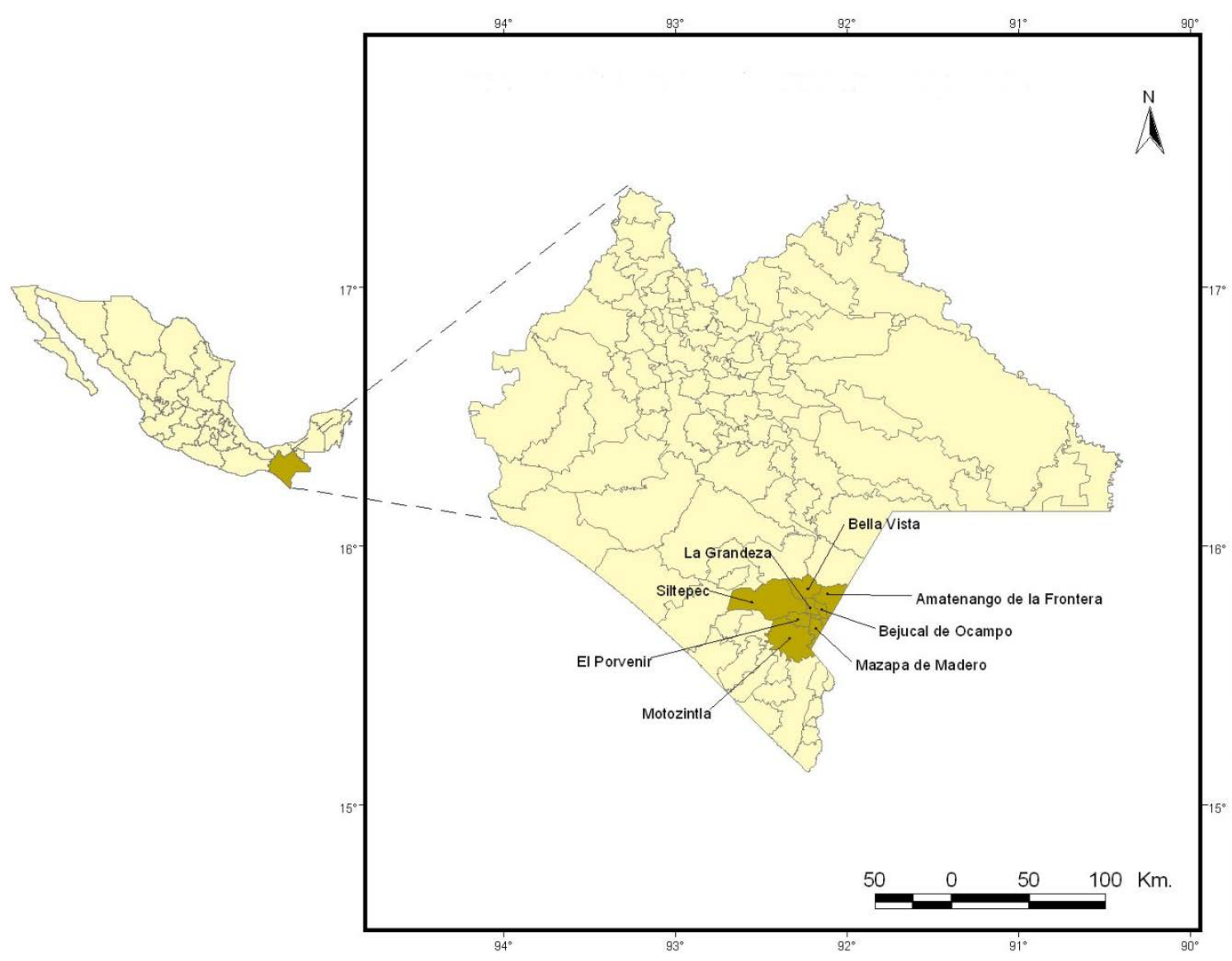

Figure 1. Localization of Chiapas state and Motozintla region with municipalities boundaries. Source: made by the authors

Motozintla has a poor communications infrastructure and within its boundaries there is no industrial or services hub of major importance. The town of Motozintla is the political hub, nevertheless even in this municipality the labour employed in agriculture reaches 57\%, the region's, eight municipalities in average have $77.9 \%$ of labour employed by the agricultural sector (INEGI 2009). From the total land area of the region $89 \%$ is under social property tenure (ejidos) the rest is under private property (INEGI 2007). The total urban land use is less than $0.1 \%$ and industrial uses are so minimal that they don't account for any percentage of the total land use statistics for the region (INEGI 2009). The climate according to Köppen is $\mathrm{Cm}$ in the higher altitudes (hill tops) and Am, Af, Aw in 
the medium and low altitudes (foot hills and intermountain valleys). The annual precipitation is highly variable between $1000 \mathrm{~mm}$ and $3000 \mathrm{~mm}$. The temperature fluctuates between 14 and $24^{\circ} \mathrm{C}$ (Erenstein and Cadena, 1997). The region is characterized for its steep-slopes that often reach more than 50\% (Figure 2) with Andosols, Acrisols and Regosols being the dominant soil types according to world reference base for soil taxonomy (SEMARNAT 2012). The eight municipalities in Motozintla have elevated poverty indexes and are considered one of the most marginal and economic depressed regions in the country (CONEVAL 2010). Motozintla farming households allocate most of their crop production to self-consumption and some small surpluses are exchanged in local markets.

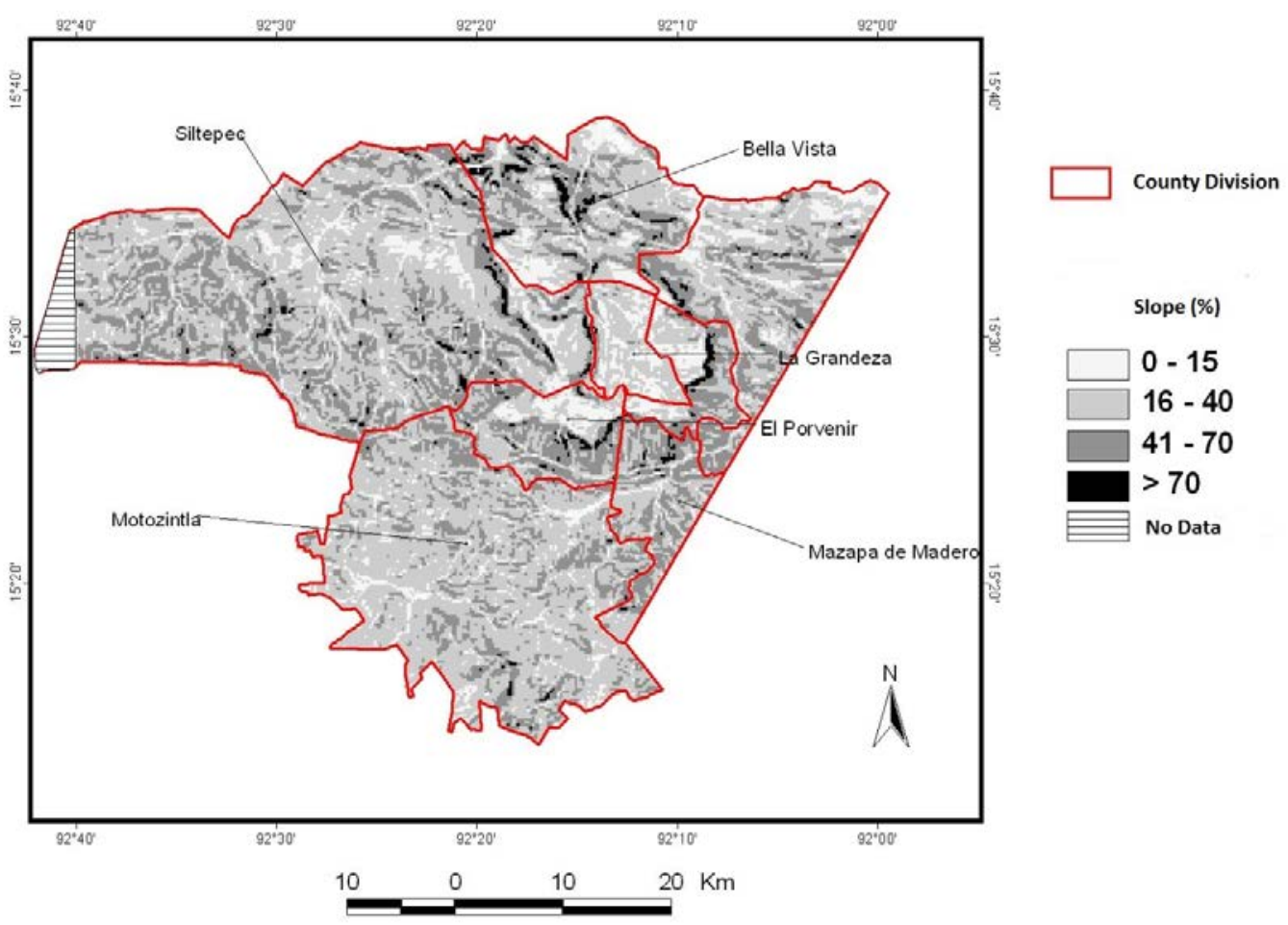

Figure 2. Slope percentages in Motozintla, Chiapas. Source: made by the authors with curve level data from INEGI, 2007

\subsection{Sampling Strategy and Survey Design}

The first part of the data was collected by CIMMYT (The International Maize and Wheat Improvement Center) and Wagenigen University in 1994 (Erenstein and Cadena 1997) to measure the production cycle of 1993, for the second part of the data a replica of the questionnaire was applied to the same sample under the coordination of CIMMYT and Instituto Mora in 2008 in order to measure the 2007 production cycle. The original sample selected for the 1994 study was drawn from a list of farmers belonging to two ejidos. One of the major critiques of this first selection in 1994 was that the two selected ejidos (El Carrizal and Tuixcum) were chosen for their proximity to Motozintla town and not randomly selected or selected for other characteristics (Erenstein and Cadena 1997). This selection bias translated in larger yields, more access to inputs, higher literacy rates and smaller household sizes than those representativesof the region. However, in order to revisit the same farmers and be able to measure changes in time this weakness was not addressed in the 2008 study where the same bias was also present.

In 1994 from a total of443 farmers in both ejidos (El Carrizal, 318; Tuixcum, 125), 82were selected for the survey (El Carrizal, 52;Tuixcum, 30). The sample was stratified byejido and the average sampling fraction was $18.5 \%$. Farm-level as well as field-level data was obtained for each of the interviewed farmers. The field on which the data was collected was selected on the basis of two criteria: size (the largest) and cropping system (maize intercropped with beans ormono- cropped maize, if the farmer didnot intercrop). Most of the survey questions focused on practices in both 1993 and 2007, although some retrospective data was collected. Aside from requesting specificinformation through the questionnaire, the enumerators in 1994 also used visual aids to estimate the slope of the selected fields and soil cover after planting. In 2008 ten farmers from the 82 interviewed in 1994 were not reachable or did not want to participate in the second interview, diminishing the sample size to 72 farmers.In one case the original interviewed farmers had died and the family member now in charge of that particular field was interviewed instead.

\subsection{Classification of the Different Production Systems}

Three different stages for crop production can be defined in the two studied ejidos. The traditional system was dominant prior to the 1985 ban of burning fields, in the 1990's two production systems were used by farmers (conventional practice and conservation agriculture), and in a third stage CA became the dominant crop production system. The typologies of the three systems present six main stages: i) pre-sowing activities, ii) sowing, iii) fertilization, iv) plague control, v) weeding, vi) harvest. Although the three systems (Traditional-CA-CP) share the same main structure some of the agricultural operations undertaken at each of these stages can be from slightly to considerably different (Table 1). 
Table 1. Overview of the typified differences of the production systems in the two studied ejidos

\begin{tabular}{|c|c|c|c|}
\hline \multicolumn{4}{|c|}{ System } \\
\hline Stage & Traditional & Conventional & Conservation \\
\hline 1)Pre-sowing & Burn of the vegetation & Cleaning ho & Paraquat-Glyphosate backpack \\
\hline Maize & $15 \mathrm{Kg} \mathrm{ha}^{-1}$ local variety & $15 \mathrm{Kg} \mathrm{ha}^{-1}$ local variety & $15 \mathrm{Kg} \mathrm{ha}^{-1}$ local variety \\
\hline procedure & Manual w & Manual with a hoe & al with a ho \\
\hline Intercropping & Phaseolus vulgaris and Cucurbita spp. & Phaseolus vulgaris and Cucurbita spp. & Phaseolus vulgaris and Cucurbita spp. \\
\hline 3)Fertilization & Organic from insitu grazing & l fractioned-Organic from in situ grazing & Chemical fractioned \\
\hline 4)Weed control & h a hoe & Manual with a hoe & Paraquat-Glyphosate backpack sprayer \\
\hline 5)Plague control & y-Sodium flu & Carbomate-Fallow & Carbomate-Fallow \\
\hline 6)Harvest & Manual-residue left for in situ grazing & Manual-residue left for in situ grazing & Manual-residues left as soil cover \\
\hline
\end{tabular}

Pre-sowing activities started in the last part of May for the three systems. In the traditional system a controlled fire was set in order to clean the fields from any vegetation, while in the conventional system the field was manually clean with a machete or a hoe and in the conservation system the weeds were controlled spraying herbicides with a backpack sprayer. Maize sowing was made in May or June, in the three system farmers would open a hole of $40 \mathrm{~cm}^{2}$ in diameter with a hoe and deposit 3-5 seeds using on average $15 \mathrm{Kg} \mathrm{ha}^{-1}$ of seed, the distance between plating stations ('cajetes' in the local terminology) is of $80-100 \mathrm{~cm}$, both within and between rows. In the CA system the farmer would use a thick wood stick('macana')before digging the hole to penetrate or move aside the residue left as soil cover, the stick is used mostly for penetrating the radicular system or to remove hard residue pieces. The local varieties used have a long physiological cycle (up to 9 months). If farmers were intercropping snap beans (Phaseolus vulgaris) and squash (Cucurbita spp.) were sow in July-August. Chemical fertilization was not accessible for the farmers in the 1980's so the fertilization was exclusively from organic sources mainly from depositions from the in situ grazing. From the 1990's onwards, chemical fertilizers were available and used fractioning a first application at around twenty days after emergence and a second 60-80 days after emergence. The main fertilizers used were Urea $\left(\mathrm{CH}_{4} \mathrm{~N}_{2} \mathrm{O}\right)$ and Ammonium Sulfate $\left(\left(\mathrm{NH}_{4}\right)_{2} \mathrm{SO}_{4}\right)$. Weed control was made manually with machete or hoe for the traditional or conventional systems. In the 1990's CA farmers used Paraquat as their main herbicide and in the 2000's they moved to Glyphosate. The most common plagues in the region are white grub (Phyllophaga spp.) in the soil and banded cucumber beetle (Diabrotica balteata)on the foliage. Plague control before the 1980's was achieved through the use of highly toxic insecticides such as mercury or sodium fluoroacetate. After the prohibition of these compounds in 1991 less toxic insecticides based on carbomates were used for both the CP and CA. In all three systems when infestations would get out of control the field was left fallow. Harvest for the three systems was done manually around January or February.

\subsection{Yield, Erosion and Household Characteristics Data}

Prior to the questionnaire farmers were asked their maize and bean (if they practiced intercropping) yields of the previous cropping cycle. Additionally to the actual yield information each farmer was asked to proportionate estimates for a good, normal and poor year yield on that same field for maize and beans(if intercropping was practiced). For both crops the three estimates plus the actual yield (as the farmer remembered it) were compared to the state of Chiapas yield average from 1987 to 2012. In the questionnaire farmers were asked about their perception of the effects of CA on their fields. In particular about soil effects and changes in weed dynamics. Farmers were also asked questions about household composition and size, household head characteristics, land use, market links and livestock ownership. All results were compared looking for changes over time that might be related to the practice of CA.

\subsection{Statistical Analysis}

The data was collected in two different points in time trying to target the same farmers. However, there were 10 unreachable farmers from the original sample. That resulted in an unequal size for the two groups and with unequal variances. In order to still be able to test hypotheses looking for mean differences for the farmers in the two points of time, we used the unequal $t$-test with Welch correction as described by Zar (1999). Unequal variance $t$-tests are an underutilized statistical method, researchers normally assume equal variances in two samples and choose to use Student's t-test without revising if the assumption of equal variance is achieved or not, unaware that Student's t-test is unreliable when variances differ between underlying populations. Moreover, when unequal variances are suspected researchers presuppose that the Mann-Whitney $U$ test can effectively substitute for Student's t-test, however this test has repeatedly been proven not to be effective in such cases (Ruxton 2006).

Welch's $t$-test defines the statistic $t$ by the following formula:

$$
t=\frac{\bar{X}_{1}-\bar{X}_{2}}{\sqrt{\frac{s_{1}^{2}}{n_{1}}+\frac{s_{2}^{2}}{n_{2}}}}
$$

where $\bar{X}_{i}$ is the sample mean, $s_{i}^{2}$ is the sample variance, and $n_{i}$ is the sample size.

\section{Results and Discussion}

\subsection{Household Characteristics, Land, Markets and Livestock Changes}

As showed in Table 2 household size and number of adult men and women haven't changed in a statistically significant way over the two points in time. However, children per household diminished in the 2007 sample, probably as a natural consequence of the maturity of the household units, were the head of the household reached 53 years old on average. The head of household stayed typically as a literate, male but logically the age and 
farming experience of the household head significantly increased in 2007 as compared to 1993. Total cultivated area and surface left on fallow didn't change. Although buying/selling of land in an ejido became legal in Mexico after a series of constitutional reforms and laws were passed in 1992 (Nuijten 2003), accumulation of land was not visible in this case study. The households were still cropping a little more than 2 hectares. For both products (maize and beans) the percentage of the production sold to the local markets didn't change either, the majority of the production was still consumed by the household itself. Livestock ownership changed significantly from 1993 to 2007. While cattle stayed more or less equal significantly less horses and sheep and significantly more pigs were recorded. The shift towards pigs instead of ruminants might have causality with the use of residue as soil cover and the change of cropping system eliminating the in situ grazing after the harvest. More research is needed to fully understand these changes and their implications.

Table 2. Two years comparison of household, head of household, market links and animal units

\begin{tabular}{lll}
\multicolumn{4}{l}{$\begin{array}{l}1993 \\
\text { mean (SD) }\end{array}$} & $\begin{array}{l}2007 \\
\text { mean (SD) }\end{array}$ \\
\hline Household Characteristics & & \\
Household Size & $5.9(1.7)$ & $5.2(2.4)$ \\
Adult Men & $2.3(1.1)$ & $2.1(1.6)$ \\
Adult Women & $1.9(1.0)$ & $1.8(1.4)$ \\
Children & $1.6(1.4)$ & $1.3(1.1)^{* * *}$ \\
Head of the Household & & \\
Age & $44(10.9)$ & $53(14.8)^{* * *}$ \\
Years as Farmer & $30(12.1)$ & $37(16.3)^{* * *}$ \\
Literacy & $96.40 \%$ & $97.30 \%$ \\
Land use & & \\
Total cultivated area & $2.1(1.2)$ & $2.3(1.7)$ \\
Fallow & $0.6(0.7)$ & $0.2(0.5)$ \\
Market links & & $32 \%(26.7)$ \\
Maize sales & $36 \%(28.7)$ & $27 \%(32.1)$ \\
Bean Sales & $31 \%(29.5)$ & \\
Animal units & & $0.7(0.4)^{* * *}$ \\
Horse & $1.7(1.1)$ & $0.3(0.6)$ \\
Cattle & $0.2(0.8)$ & $1.9(4.6)^{* *}$ \\
Sheep & $2.6(5.2)$ & $1.2(1.3)^{* * *}$ \\
Pig & $0.3(1.1)$ & $p<0.05$ or $* * * p$ \\
\hline Significant differences are indicated with $* p<0.1, * *$ & \\
$<0.01$. & &
\end{tabular}

\subsection{Maize and Bean Yields}

There was a statistically significant increment in all four maize yield parameters (actual yield; good, normal and poor yield estimate) when 1993 and 2007 were compared. Also in 2007 the yields in the two ejidos were still consistently larger than the state of Chiapas average (Figure 3). The observed yield increment hasn't been as large as reported from other studies carried out in similar semi-arid conditions (Erenstein 2002; Romero-perezgrovas et al. 2014). In the case of beans no significant difference was found between the two years (1993 and 2007) for the actual yield and the normal yield estimates, while there was a significant increase in the poor yield estimate in favour of 2007 and also for the good year estimate there was some evidence for different means in favour of 2007 $(\mathrm{p}<0.1)$ (Table 3). However, comparing the bean yields with the state averages time series from 1987 to 2012 shows clearly that beans produced in the CA intercropping system of the two studied ejidos had lower yields than the state of Chiapas average (Figure 4). However, it's important to stress that the state average is built primarily with data from monocropped bean fields.

Table 3. Maize and beans yield estimate comparison

\begin{tabular}{lllll}
\hline & $\begin{array}{l}\text { 1993-Sample } \\
\text { mean (SD) }\end{array}$ & $\begin{array}{l}\text { 1993-CP } \\
\text { mean }\end{array}$ & $\begin{array}{l}\text { 1993-CA } \\
\text { mean }\end{array}$ & $\begin{array}{l}\text { 2007-Sample } \\
\text { mean (SD) }\end{array}$ \\
\hline Maize ton ha & & & & \\
Actual & $2.6(0.6)$ & 2.7 & 2.9 & $3.3(0.7)^{* * *}$ \\
Good year & $3.1(0.8)$ & 2.9 & 3.7 & $3.6(1.0)^{* * *}$ \\
Normal year & $2.3(0.5)$ & 2.1 & 2.6 & $2.9(0.6)^{* * *}$ \\
Poor year & $1.5(0.5)$ & 1.4 & 1.7 & $2.4(0.9)^{* * *}$
\end{tabular}

Beans $\mathrm{Kg} \mathrm{ha}^{-1}$

\begin{tabular}{lllll} 
Actual & $267(88)$ & 240 & 301 & $262(93)$ \\
Good year & $318(107)$ & nd & nd & $323(116)^{*}$ \\
Normal year & $212(90)$ & 208 & 248 & $236(102)$ \\
Poor year & $115(70)$ & 104 & 148 & $150(87)^{* * *}$ \\
\hline $\begin{array}{l}\text { Significant differences are indicated with } \\
<0\end{array}$ \\
$<0.01$.
\end{tabular}
$<0.01$.

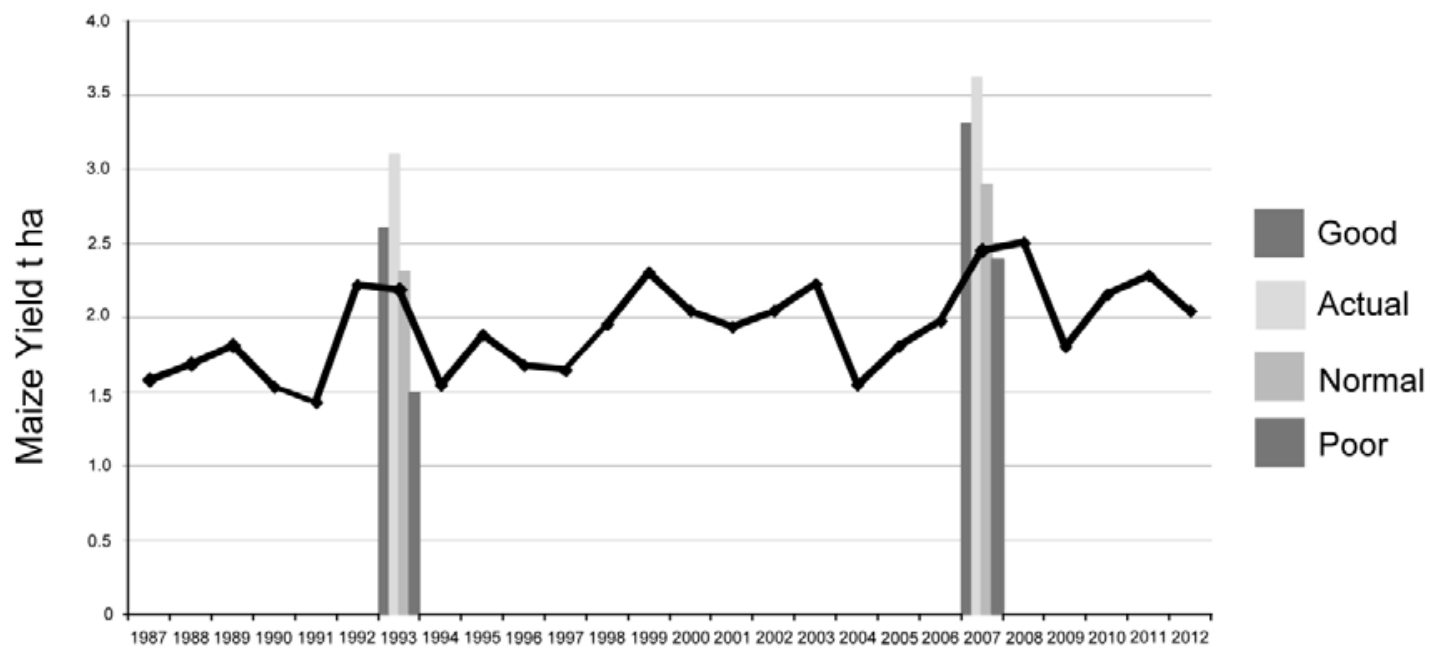

Year

Figure 3. Maize yield comparisons for good, actual, normal and poor year estimates in 1993 and 2007 including long-term Chiapas state's maize yieldaverages 


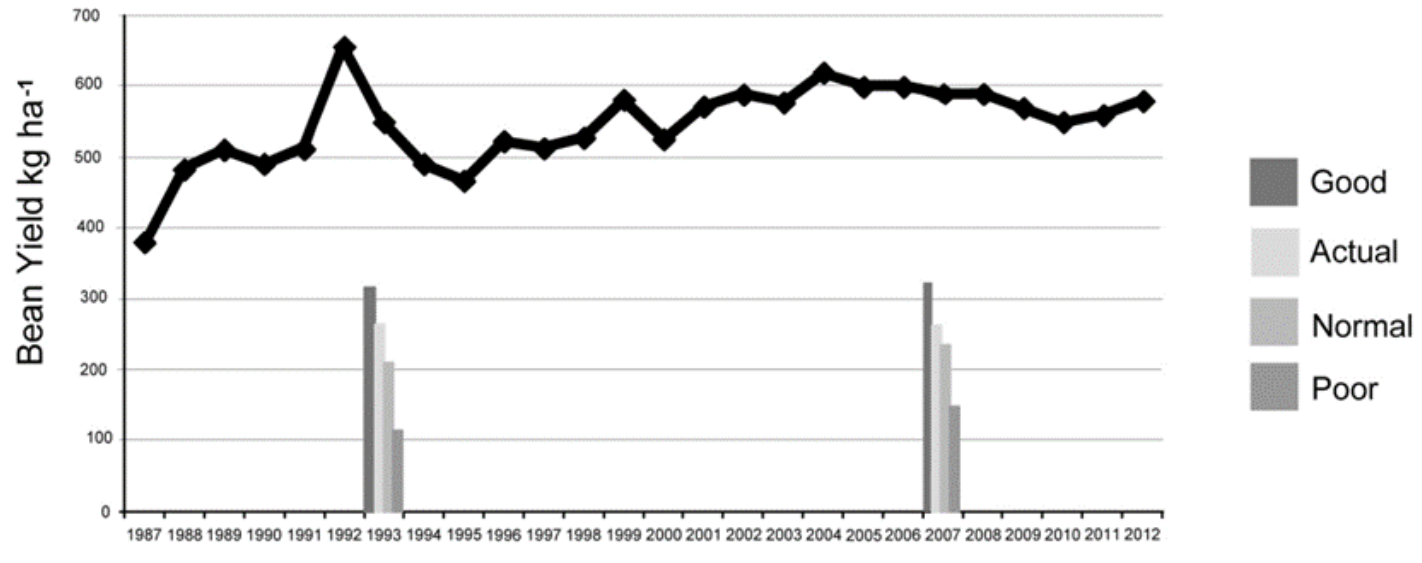

Year

Figure 4. Bean yield comparisons for good, actual, normal and poor year estimates in 1993 and 2007 including long-term Chiapas state's bean yieldaverages

\subsection{Farmers' Perceptions of CA Effects on the Soil}

All interviewed farmers in both years except one in 2007 agreed that CA through the mulch component was a main driver for soil erosion control (Table 4). Farmers' perception is corroborated by scientific evidence that started with Shaxon's et al. studies in 1989 and has been continuously accumulating (Lal and Stewart 2013). Soil compaction was not perceived as a problem in neither years, it's important to clarify that mechanisation the primary driver of soil compaction in agricultural land (Friedrich et al. 2012) is almost impossible on steep-slopes without intensive investments (terracing, levelling, etc.) and in the studied area mechanization on the slopes is non-existent. In both years the majority of farmers perceived that CA was increasing soil moisture and fertility on their fields. In fact there are reports on the potential of CA to increase soil moisture (Verhulst et al 2011) or yields (Knowler and Bradshaw 2007) although there are also instances were yield improvements were not observed (Brouder and Gomez-Macpherson 2014). The only main shift in farmers' perception was on the issue of weeds. Perennial weeds such as Cynodon Dactylon that were already a concern in 1993, were clearly acknowledged as a problem related to CA by 56\% of the interviewed farmers in 2007 (Table 4). Shifts in weed community composition have been observed in CA systems with densities of some annual and perennial weeds increasing (Moyer et al. 1994). But as Locke et al. (2002) point out in their review a number of factors (i.e. location, crop, soil type and management practices) influence possible weed shifts. Further the use of a single herbicide over an extended period of time can cause resistant biotypes to develop (Chauhan et al. 2012). And as Farooq et al. (2011) conclude from an analysis of 25 experiments comparing CA with conventional tillage systems "evolved weed resistance to herbicides remains one of the greatest challenges to CA yields and long-term sustainability”. Thus, and especially in light of farmers concern about the weed shifts they observed, it is important to foster technical support and availability of a range of herbicides to enable farmers to have the best possible weed control and avoid yield penalties that could incur because of inadequate weed management.
Table 4. Farmers perceptions on conservation agriculture effects

\begin{tabular}{lcc}
\hline & $\mathbf{1 9 9 3}$ & $\mathbf{2 0 0 7}$ \\
\hline CA Increases Soil Compaction (No) & $93 \%$ & $96 \%$ \\
CA increases Weed Problems (No) & $93 \%$ & $43 \%$ \\
CA Increases Soil Moisture (Yes) & $92 \%$ & $93 \%$ \\
CA Increases Soil Fertility (Yes) & $84 \%$ & $90 \%$ \\
CA Reduces Soil Erosion (Yes) & $100 \%$ & $99 \%$ \\
\hline
\end{tabular}

\section{Conclusions}

Conservation agriculture expanded in the two ejidos from 1985 onwards, after burning of fields was forbidden, and by 2007 CA was established as the dominant cropping system. Farmers perceived that CA had been improving soil fertility and moisture as well as effectively controlling soil erosion. Maize yields in the study area recorded a statically significant increment through time and they are still clearly above the long term state average. The traditional system in this two ejidos was characterized by some factors that had a positive influence on CA implementation: farmers had no mechanisation and intercropping was already a common practice. Additionally the change in law that forbid agricultural fires and local institutional changes to enforce this law was a major driver towards CA adoption as it pushed farmers to explore new ways of producing. The use of residue as soil cover instead of fodder had a negative impact on ruminants ownership (we recorded a clear decreased on horses and sheep). However ruminants were eventually substituted with pigs (their number significantly increased) and horse decrements could possibly also be linked to increments in motorised transport.

The findings of this study are specific to the two ejidos were the data was gathered. We doubt that the findings can be extrapolated to a regional level, because of two issues: (1) the two ejidos are not representative for the whole region and (2) an intervention to stimulate CA adoption had taken place in the study area with the distribution of free back pack sprayers at the beginning of the 1990's. However for the study area we showed that through CA producers on steep-slopes sustained maize and bean yields through time and controlled erosion. The reduction of soil erosion on the steep-slopes provides 
positive externalities (less sediments into the hydroelectrically system, better water infiltration and less landslides) and governments do not have to spend resources on the creation and maintenance of physical barriers or engineering works, however, farmers are not able to directly capture any of the produced savings for third parties. Total income measurements were out of reach for this study but we fear that the positive yield and fertility trends captured are not necessarily helping farmer households to increase their income, especially as there is no return from the positive externalities provided. Still the two ejidos have better poverty indicators than the region averages, so at least we can exclude a clear negative effect of CA on social and economic indicators when compared to the rest of the region. Why CA adoption has not happened in other neighbouring ejidos as well as the income effects at household level are topics that should be researched in the future, forlornly addressing this issues was out of reach for this particular research.

\section{Acknowledgement}

The authors would like to thank Olaf Erenstein, Pedro Cadena and Dagoberto Flores whom started the study in 1994 and facilitated the original surveys. We are very grateful for all the logistics help offered by the DDR 07 in Motozintla and thank in particular Urbano Martinez. The Mexican National Commission for Science and Technology (CONACYT) is acknowledged for the financial support. And the International Maize and Wheat Improvement Center (CIMMYT) and Instituto Mora are acknowledged for all the support, in particular we would like to thank Bram Goaverts, Erenest Sánchez-Santiró and Alfredo Pureco.

\section{References}

[1] Altieri, M. A., Funes-Monzote, F. R., and Petersen, P. (2012). Agroecologically efficient agricultural systems for smallholder farmers: contributions to food sovereignty. Agronomy for Sustainable Development, 32(1), 1-13.

[2] Amsalu, A., \& De Graaff, J. (2007). Determinants of adoption and continued use of stone terraces for soil and water conservation in an Ethiopian highland watershed. Ecological Economics, 61(2), 294-302.

[3] Brouder, S. M., \& Gomez-Macpherson, H. (2014). The impact of conservation agriculture on smallholder agricultural yields: A scoping review of the evidence. Agriculture, Ecosystems \& Environment, 187, 11-32.

[4] Chauhan, B. S., Singh, R. G., \& Mahajan, G. (2012). Ecology and management of weeds under conservation agriculture: a review. Crop Protection, 38, 57-65.

[5] CONEVAL. (2010). Multidimensional Poverty Measurement. CONEVAL.

[6] Erenstein, O. (2003). Smallholder conservation farming in the tropics and sub-tropics: a guide to the development and dissemination of mulching with crop residues and cover crops. Agriculture, Ecosystems \& Environment, 100(1), 17-37.

[7] Erenstein, O., \& Iñiguez, P. C. (1997). The adoption of conservation tillage in a hillside maize production system in Motozintla, Chiapas (Vol. 97, No. 1). CIMMYT.

[8] Farooq, M., Flower, K. C., Jabran, K., Wahid, A., \& Siddique, K. H. (2011). Crop yield and weed management in rainfed conservation agriculture. Soil and Tillage Research, 117, 172-183.

[9] Friedrich, T., Kienzle, J., \& Kassam, A. (2012). A new paradigm for sustainable intensification and its implications for agricultural mechanization. In Rural Development. International Conference of Agricultural Engineering-CIGR-AgEng 2012: agriculture and engineering for a healthier life, Valencia, Spain, 8-12 July 2012. (pp. P-0416). CIGR-EurAgEng.

[10] Giller, K. E., Witter, E., Corbeels, M., \& Tittonell, P. (2009). Conservation agriculture and smallholder farming in Africa: the heretics' view. Field crops research, 114(1), 23-34.

[11] INEGI. (2007), Censo Agropecuario. INEGI.

[12] INEGI. (2009), Censo Economico. INEGI.

[13] Knowler, D., \& Bradshaw, B. (2007). Farmers' adoption of conservation agriculture: A review and synthesis of recent research. Food policy, 32(1), 25-48.

[14] Lal, R. (1990). Soil erosion in the tropics: principles and management. McGraw Hill.

[15] Lal, R., \& Stewart, B. A. (Eds.). (2013). Principles of sustainable soil management in agroecosystems. CRC Press.

[16] Locke, M. A., Reddy, K. N., \& Zablotowicz, R. M. (2002). Weed management in conservation crop production systems. Weed Biology and management, 2(3), 123-132.

[17] Lutz, E., Pagiola, S., \& Reiche, C. (1994). THE COSTS AND BENEFITS OF SOIL CONSERVATION: THE FARMERS'VIEWPOINT. The World Bank Research Observer, 9(2), 273-295.

[18] Moyer, J. R., Roman, E. S., Lindwall, C. W., \& Blackshaw, R. E. (1994). Weed management in conservation tillage systems for wheat production in North and South America. Crop Protection, 13(4), 243-259.

[19] Nuijten, M. (2003). Family property and the limits of intervention: The Article 27 reforms and the PROCEDE programme in Mexico. Development and Change, 34(3), 475-497.

[20] Romero-perezgrovas, R., Verhulst, N., De La Rosa, D., Hernández, V., Maertens, M., Deckers, J., \& Govaerts, B. (2014). Effects of Tillage and Crop Residue Management on Maize Yields and Net Returns in the Central Mexican Highlands Under Drought Conditions. Pedosphere, 24(4), 476-486.

[21] Ruxton, G. D. (2006). The unequal variance t-test is an underused alternative to Student's t-test and the Mann-Whitney U test. Behavioral Ecology, 17(4), 688-690.

[22] Shaxson, T. F., Hudson, N. W., \& Sanders, D. W. (1989). Land husbandry: a framework for soil and water conservation (pp. 164). Soil and Water Conservation Society.

[23] SEMARNAT. (2012), Los Suelos de Mexico. SEMARNAT

[24] Stevenson, J. R., Serraj, R., \& Cassman, K. G. (2014). Evaluating conservation agriculture for small-scale farmers in Sub-Saharan Africa and South Asia. Agriculture, Ecosystems \& Environment, 187, 1-10.

[25] Tuan, V. D., Hilger, T., MacDonald, L., Clemens, G., Shiraishi, E., Vien, T. D., and Cadisch, G. (2014). Mitigation potential of soil conservation in maize cropping on steep slopes. Field Crops Research, 156, 91-102.

[26] Verhulst, N., Govaerts, B., Sayre, K. D., Sonder, K., RomeroPerezgrovas, R., Mezzalama, M., \& Dendooven, L. (2011). Conservation agriculture as a means to mitigate and adapt to climate change, a case study from Mexico. Designing agricultural mitigation for smallholders in developing countries.

[27] Zar, J. H.(1999) Biostatistical Analysis, 4th edn, Prentice Hall. 